\title{
IgA nephropathy in a patient receiving infliximab for generalized pustular psoriasis
}

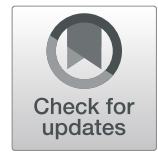

\author{
Yuka Segawa', Ryo Ishida', Fuminao Kanehisa², Kunihiro Nakai ${ }^{1}$, Mari Morimoto², Masafumi Seno', \\ Mayuka Nakayama', Tetsuro Kusaba' ${ }^{1}$ Norito Katoh ${ }^{2}$ and Keiichi Tamagaki ${ }^{{ }^{*}}$ (D)
}

\begin{abstract}
Background: IgA nephropathy is the most common glomerulonephritis. Secondary IgA nephropathy complicated with systemic diseases, including psoriasis, is also often reported. Generalized pustular psoriasis is a form of psoriasis characterized by sterile pustules on reddened skin and fever. Infliximab, one of the first-line therapies for severe psoriasis, has also been reported to cause systemic vasculitis and IgA nephropathy. We herein report a case of IgA nephropathy activated during infliximab treatment for generalized pustular psoriasis.

Case presentation: A 28-year-old woman presented with episodic gross hematuria, increasing proteinuria, and renal dysfunction. She had been receiving anti-TNFa therapy with infliximab because of generalized pustular psoriasis for 3 years, but her skin symptoms worsened following withdrawal during pregnancy. After delivery, her skin symptoms improved with the resumption of infliximab, but clinical signs suggested glomerulonephritis, and renal biopsy showed active IgA nephropathy. Infliximab was discontinued, and the combination of corticosteroids, tonsillectomy, and secukinumab, an IL-17A inhibitor, improved both the skin symptoms and the glomerulonephritis.

Conclusions: In our case, the activity of IgA nephropathy was exacerbated by anti-TNFa therapy but was improved by the combination of corticosteroids, tonsillectomy, and an IL-17A inhibitor against the original disease.

Autoimmune diseases may underlie the development of secondary IgA nephropathy associated with anti-TNFa therapy, and so further studies are needed to better understand the association between molecular-targeted drugs and IgA nephropathy.
\end{abstract}

Keywords: IgA nephropathy, Generalized pustular psoriasis, Infliximab, TNFa, Secukinumab, IL-17

\section{Background}

IgA nephropathy (IgAN) is the most common glomerulonephritis. It manifests a variety of clinical courses, often shows persistent hematuria, and sometimes shows macroscopic hematuria associated with mucosal infections. IgAN is an autoimmune disorder in which IgA1IgG immune complexes deposit on the mesangium and cause inflammation. The immunogenicity of IgA1 is due to an IgA1 galactosylation defect [1]. Secondary IgAN complicated with systemic diseases, such as liver

\footnotetext{
* Correspondence: tamagaki@koto.kpu-m.ac.jp

'Division of Nephrology, Department of Medicine, Kyoto Prefectural University of Medicine, 465 Kajii-cho, Kamigyo-ku, Kyoto 602-8566, Japan Full list of author information is available at the end of the article
}

cirrhosis, rheumatoid arthritis, inflammatory bowel disease, and other autoimmune diseases, is also often reported [2].

Generalized pustular psoriasis (GPP) is a form of psoriasis characterized by the presence of sterile pustules on reddened skin covering almost the entire body, frequently accompanied by fever. The prevalence of GPP is only about $1 \%$ among cases of psoriasis. It has been emphasized that psoriasis is a systemic chronic inflammatory disease rather than a skin disease $[3,4]$.

We report a case of IgAN activated during infliximab treatment for GPP and discuss the relationships among the two diseases and anti-TNFa therapy.

(C) The Author(s). 2020 Open Access This article is licensed under a Creative Commons Attribution 4.0 International License, which permits use, sharing, adaptation, distribution and reproduction in any medium or format, as long as you give appropriate credit to the original author(s) and the source, provide a link to the Creative Commons licence, and indicate if changes were made. The images or other third party material in this article are included in the article's Creative Commons licence, unless indicated otherwise in a credit line to the material. If material is not included in the article's Creative Commons licence and your intended use is not permitted by statutory regulation or exceeds the permitted use, you will need to obtain permission directly from the copyright holder. To view a copy of this licence, visit http://creativecommons.org/licenses/by/4.0/ The Creative Commons Public Domain Dedication waiver (http://creativecommons.org/publicdomain/zero/1.0/) applies to the data made available in this article, unless otherwise stated in a credit line to the data. 


\section{Case presentation}

A 28-year-old woman was referred to our hospital for episodic gross hematuria, increasing proteinuria, and renal dysfunction. She was diagnosed with GPP at the age of 2 years. Her father also suffered from GPP. Although GPP remained in remission for a long time, her skin symptoms deteriorated with pregnancy at the age of 24, around the same time as microscopic hematuria appeared. Corticosteroids were started, and both the skin symptoms and urinary findings improved after delivery. Anti-TNF $\alpha$ therapy with infliximab was initiated at the age of 25. Although her skin symptoms were relieved by the anti-TNF $\alpha$ therapy, she experienced two episodes of gross hematuria associated with throat infections. At the age of 27, her skin symptoms deteriorated when infliximab was discontinued during her second pregnancy, but improved with the resumption of infliximab after childbirth. Serum creatinine levels, hematuria, and urinary protein gradually worsened with upper respiratory infection (from $0.5 \mathrm{mg} / \mathrm{dl}, 30-49 / \mathrm{HPF}$, and negative, to $0.87 \mathrm{mg} / \mathrm{dl},>100 / \mathrm{HPF}$, and $3.04 \mathrm{~g} / \mathrm{gCr}$, respectively) (Fig. 1). When she first visited our hospital, there was mild enlargement of the bilateral palatine tonsils on physical examination. There were no findings suggesting IgA vasculitis such as fever, purpura, arthralgia, or abdominal pain. Her blood pressure was 107/65 $\mathrm{mmHg}$. There were no medications other than infliximab. The laboratory workup performed on her first visit showed hematuria, proteinuria, and mild renal dysfunction (Table 1).
A renal biopsy was performed to clarify the diagnosis at 3 years after the initiation of anti-TNF $\alpha$ therapy which was 1 month after the second course of infliximab was discontinued and a little over 2 months after the end of the second pregnancy. A total of 33 glomeruli were included in the renal biopsy samples. Most glomeruli showed segmental mesangial proliferation (Fig. 2a). Three glomeruli showed global sclerosis and one glomerulus showed segmental sclerosis. Seven glomeruli showed crescents, including three cellular (Fig. 2b), three fibrocellular, and one fibrous crescent. Interstitial fibrosis was found in $10 \%$ of the renal cortex. There was slight arteriosclerosis but no vasculitis. Immunofluorescence microscopy showed positive staining for IgA and $\mathrm{C} 3$ in the mesangial areas (Fig. 2c, d). On electron microscopy, electron-dense deposits were evident in the mesangial and paramesangial areas, and segmental moderate subendothelial edema was observed (Fig. 2e).

The diagnosis was IgA nephropathy: M1 E0 S1 T0 C1, according to the Oxford classification [5]. In addition, segmental subendothelial edema on electron microscopy suggested the effect of pregnancy.

After discontinuing infliximab and observing whether serum creatinine and urinary findings improved, intravenous corticosteroid pulse therapy was started 28 days after the renal biopsy. Intravenous methylprednisolone for 3 days at a dose of $0.5 \mathrm{~g}$ daily was given for three courses every 40 days. As a follow-up treatment, prednisolone at a dose of $30 \mathrm{mg}$ every other day was administered, but the dose was changed to $15 \mathrm{mg}$ daily because of postprandial hyperglycemia and considering that she was lactating.

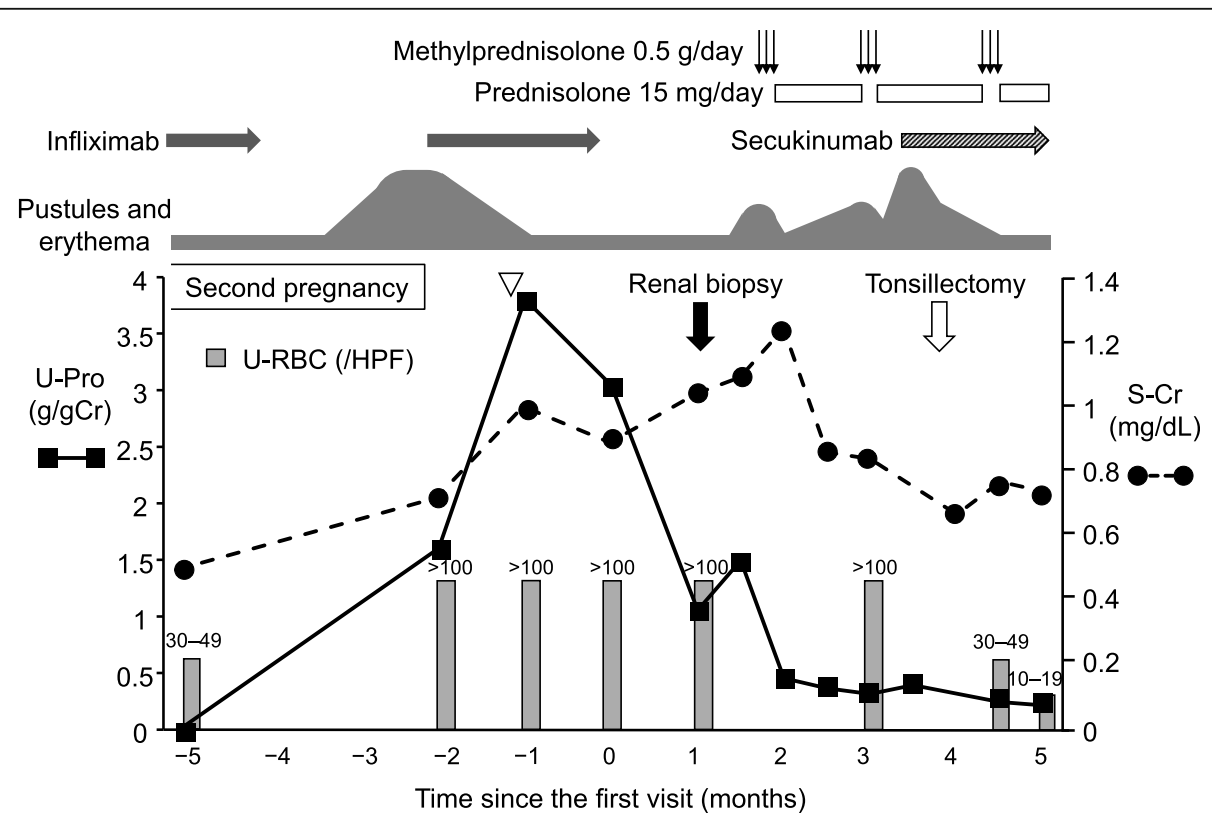

Fig. 1 Clinical course. After second child birth, macroscopic hematuria, increase in urinary protein, and elevation of serum creatinine levels occurred with an upper respiratory infection (white arrowhead). S-Cr: serum creatinine, U-Pro: urinary protein, U-RBC: urinary red blood cells 
Table 1 Laboratory data at first visit

\section{Peripheral blood}

WBC
RBC
$\mathrm{Hb}$
$\mathrm{Hct}$
Plt

6500

$380 \times 10^{4}$

11.0

33.6

$30.7 \times 10^{4}$

Blood chemistry

TP

Alb

AST

ALT

LDH

UA

BUN

$\mathrm{Cr}$

$\mathrm{Na}$

K

Cl

$\mathrm{Ca}$

IP

CRP

$\mathrm{HbA1c}$

Serological tests

$\lg G$

$\lg A$

IgM

Serological tests

C3

C4

$\mathrm{CH} 50$

ANA

MPO-ANCA

PR3-ANCA

Urinalysis

Gravity
pH
Protein
Occult blood
Sediments
RBC
WBC
Epithelial cells

Urine chemistry

Protein

NAG
6.5

3.7

12

7

180

4.9

25.5

0.87

142

4.1

108

8.8

4.2

0.03

5.8

1077

332

128

87.8

30.7

45.3

$<1: 40$

$<1.0$

2.0

1.017

6.0

$3+$

$3+$

$$
\begin{aligned}
& >100 \\
& 1-4 \\
& 1-4
\end{aligned}
$$

/ HPF

/ HPF

/ HPF

$/ \mu \mathrm{L}$

$/ \mu \mathrm{L}$

$\mathrm{g} / \mathrm{dL}$

$\%$

$/ \mu \mathrm{L}$

g/dL

$\mathrm{g} / \mathrm{dL}$

U/L

$\mathrm{U} / \mathrm{L}$

U/L

$\mathrm{mg} / \mathrm{dL}$

$\mathrm{mg} / \mathrm{dL}$

$\mathrm{mg} / \mathrm{dL}$

$\mathrm{mEq} / \mathrm{L}$

$\mathrm{mEq} / \mathrm{L}$

$\mathrm{mEq} / \mathrm{L}$

$\mathrm{mg} / \mathrm{dL}$

$\mathrm{mg} / \mathrm{dL}$

$\mathrm{mg} / \mathrm{dL}$

$\%$

$\mathrm{mg} / \mathrm{dL}$

$\mathrm{mg} / \mathrm{dL}$

$\mathrm{mg} / \mathrm{dL}$

$\mathrm{mg} / \mathrm{dL}$

$\mathrm{mg} / \mathrm{dL}$

$\mathrm{mg} / \mathrm{dL}$

$/ \mathrm{mL}$

$/ \mathrm{mL}$

$\mathrm{g} / \mathrm{gCr}$

$\mathrm{U} / \mathrm{gCr}$ 
Table 1 Laboratory data at first visit (Continued)

\begin{tabular}{llc}
\hline$\beta 2-m$ & 216 & $\mu g / g C r$ \\
Casts & & WF \\
Epithelial & $5-9$ & WF \\
RBC & $1-4$ & WF \\
Granular & $1-4$ & WF \\
Hyaline & $1-4$ & WF \\
\hline
\end{tabular}

Serum creatinine was reduced but the urine findings did not sufficiently improve. Inflammation of the skin was initially relieved by the first pulse therapy, but the oral corticosteroid was not sufficient to maintain her skin condition. Pustules and erythema worsened despite the second pulse therapy. Secukinumab, an anti-IL-17A monoclonal antibody, was initiated and administered at $300 \mathrm{mg}$ subcutaneously at weeks $0,1,2,3$, and then every 4 weeks, which controlled the skin symptoms. Bilateral tonsillectomy was performed 93 days after the renal biopsy. Serum creatinine decreased to the normal range and urine findings gradually improved (Fig. 1). The patient was transferred due to relocation, and her urinary protein and urinary red blood cells remained at low levels.

\section{Discussion and conclusion}

There are some reports that psoriasis is associated with glomerular disease. IgAN is the most frequent [6], and mesangial proliferative nephritis [7], amyloidosis [8], focal segmental glomerulosclerosis [9], minimal change disease [10], and membranoproliferative glomerulonephritis [11] have also been reported. However, as far as GPP is concerned, there are few reports of glomerulonephritis. Secondary IgAN often worsens or improves with the activity of the original disease $[6,12]$, but sometimes it does not $[13,14]$. In the present case, the initial onset of hematuria and its response to glucocorticoids were consistent with the skin symptoms, and there was no macroscopic hematuria with upper respiratory infection. However, after starting anti-TNF $\alpha$ therapy, the clinical activity of IgAN continued to deteriorate without relation to the skin disease, and there was macroscopic hematuria with upper respiratory infection. This clinical course suggested that anti-TNF $\alpha$ therapy exacerbated IgAN and that IgAN was associated with GPP. In addition, pregnancy is obviously considered to be an

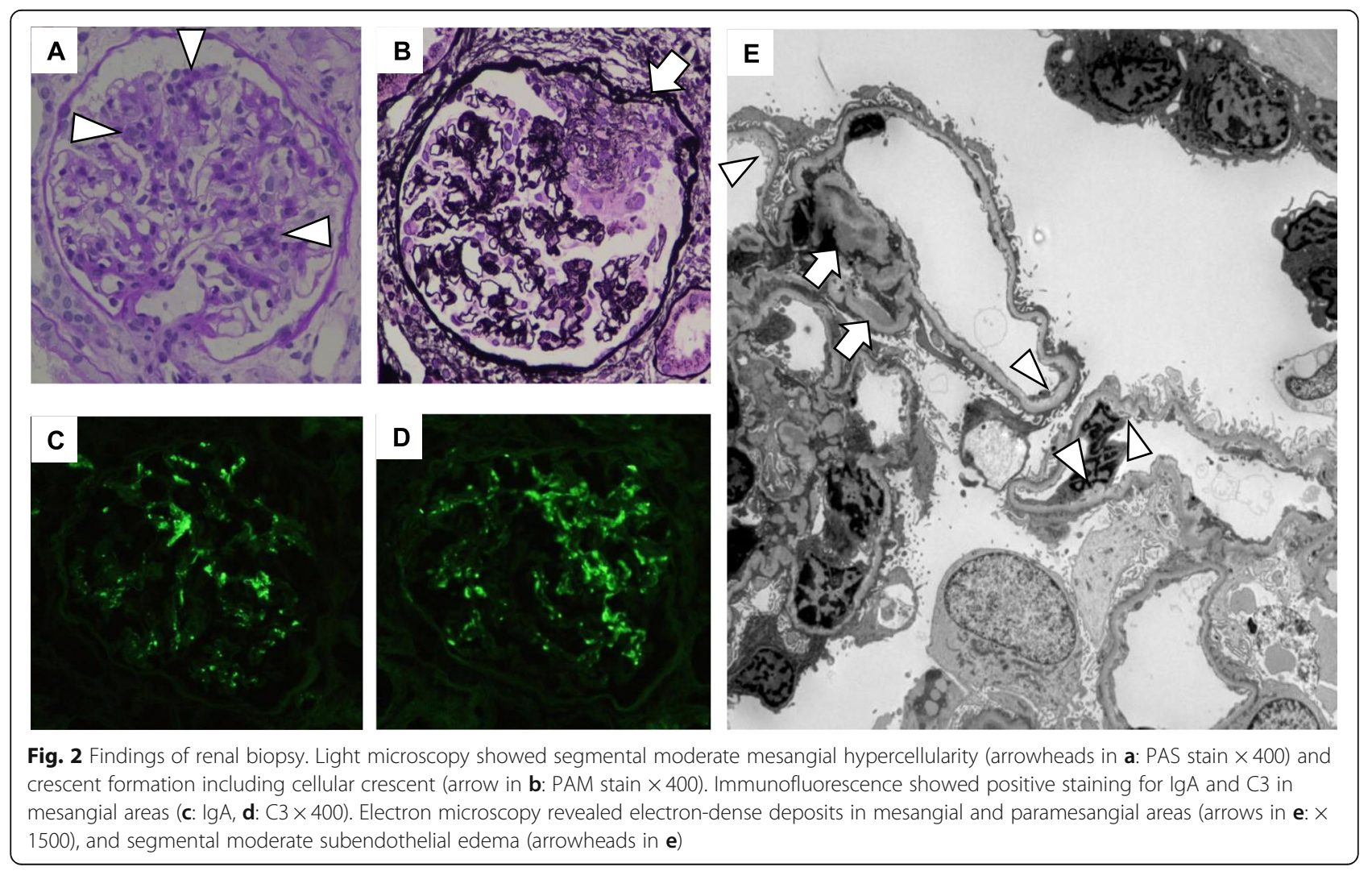


exacerbatory factor in GPP, and could be related with proteinuria through endothelial dysfunction. Therefore, pregnancy may have contributed to the increased activity of GPP and possibly IgAN in our case.

The guidelines of the Medical Board of the National Psoriasis Foundation recommend acitretin, cyclosporine, methotrexate, or infliximab as first-line therapies for adult GPP. Although the data are limited, first-line therapy for pregnant women with GPP includes cyclosporine, oral corticosteroids, and topical agents. Because of its rapid onset of effect, infliximab is considered the first-line treatment especially in patients with severe and extensive disease [15]. Although tonsillectomy is not a standard treatment for GPP, there are some reports of its efficacy in psoriasis [16-18]. Therefore, tonsillectomy was performed as a possible treatment for both IgAN and GPP. In recent years, successful treatments of GPP with various biologic agents have been reported. Most recently, secukinumab, an IL-17A inhibitor, has shown promising ability to resolve symptoms rapidly in the treatment of GPP [3]. The efficacy of secukinumab has been shown in an interventional study [4], and its use is expected to increase.

Infliximab is an anti-TNFa monoclonal antibody that binds TNF with high affinity and has been widely used in recent years as a therapeutic agent for autoimmune diseases, with few side effects. As for pustular psoriasis, the TNFo inhibitors are central therapeutic agents as mentioned above $[3,15]$. However, TNF $\alpha$ inhibitors have been reported to induce systemic vasculitis [19] and several types of glomerulonephritis, such as minimal change disease, membranous nephropathy, IgA nephropathy, pauci-immune necrotizing GN, and lupus-like nephritis [13, 20-24]. The mechanisms of vasculitis associated with anti-TNF $\alpha$ therapy are unclear, although the following hypotheses have been suggested: 1) TNF $\alpha$ / antiTNF $\alpha$ immune complexes may deposit on small vessels and induce local complementary activation; and 2) the cytokine imbalance, with a shift from a Th1 to a Th2 profile, may promote the development of manifestations related to antibody-mediated immunity [25]. For glomerulonephritis, it is hypothesized that immune complexes are formed by a cross-reaction of the galactose-deficient IgA1 (Gd-IgA1) and the anti-drug antibodies against the glycan structures of TNF $\alpha$ inhibitors. These deposit on the mesangium, leading to IgAN [26]. In addition, the reported rate of detection of antinuclear antibodies in patients treated with anti-TNFo therapy is $29-76.7 \%$. The immunological abnormalities can induce glomerulonephritis, such as membranous glomerulonephritis and lupus nephritis [23, 27]. In our case, macroscopic hematuria with upper respiratory infection and proteinuria became obvious after the initiation of anti-TNF $\alpha$ therapy, suggesting that underlying IgAN may have been exacerbated due to acceleration of IgA1 deposition by the TNF $\alpha$ inhibitor.

IL-17 expression increases locally in the skin in pustular psoriasis [28], and its inhibition is indicated as a specific treatment. IL-17 and keratinocytes are key factors in the development of psoriasis [29]. IL-17-producing CD4+ helper $\mathrm{T}$ (Th17) cells create a self-amplifying response that is markedly augmented in the presence of TNF- $\alpha$, and Th17 cells produce high amounts of TNF- $\alpha$ [30-32]. Therefore, IL-17 and TNF- $\alpha$ are major drivers in the pathogenesis of psoriasis. In IgA nephropathy, IL17 is also a key mediator of inflammation. IL-17 is considered to induce Gd-IgA1 production leading to the development of IgAN [33]. In addition, an imbalance of the regulatory $\mathrm{T}$ cell to Th17 cell ratio in IgA nephropathy patients has been suggested to play a role in disease pathogenesis and progression [34]. Moreover, serum/ urinary IL-17A is elevated in IgAN patients compared with other nephropathy and control groups [35]. Thus, the inhibition of IL-17A may be effective not only against psoriasis but also against IgAN to some extent. Indeed, the urinary findings that were not improved by corticosteroids alone improved after the initiation of secukinumab in our case, which suggests the efficacy of the IL-17A inhibitor.

In conclusion, we experienced a case of IgAN associated with GPP. The activity of IgAN was exacerbated by anti-TNF $\alpha$ therapy but was improved by the combination of corticosteroids, tonsillectomy, and an IL-17A inhibitor against the original disease. Autoimmune diseases may underlie the development of secondary IgAN associated with anti-TNF $\alpha$ therapy, and so further studies are needed to better understand the association between molecular-targeted drugs and IgAN.

Abbreviations

IgAN: IgA nephropathy; GPP: Generalized pustular psoriasis

\section{Acknowledgements}

Not applicable.

\section{Authors' contributions}

YS collected clinical information and drafted the manuscript. RI supported data collection, its interpretation, and writing of the manuscript. KN, MM, MS, $M N$, TK and $K T$ are the original physicians of the patient. FK and NK are the dermatologists of the patient. KT helped to draft the manuscript and was responsible for critical revision of the manuscript for important intellectual content. All authors were involved in the revision of the draft manuscript and approved the final content.

\section{Funding \\ None.}

Availability of data and materials Not applicable.

Ethics approval and consent to participate Not applicable. 


\section{Consent for publication}

Written informed consent was obtained from the patient for publication of this Case report and any accompanying images. A copy of the written consent is available for review by the Editor of this journal.

\section{Competing interests}

The authors declare that they have no competing interests.

\section{Author details}

${ }^{1}$ Division of Nephrology, Department of Medicine, Kyoto Prefectural University of Medicine, 465 Kajii-cho, Kamigyo-ku, Kyoto 602-8566, Japan. ${ }^{2}$ Department of Dermatology, Kyoto Prefectural University of Medicine, 465 Kajii-cho, Kamigyo-ku, Kyoto 602-8566, Japan.

Received: 26 December 2019 Accepted: 11 August 2020 Published online: 26 August 2020

\section{References}

1. Barratt J, Feehally J. IgA nephropathy. J Am Soc Nephrol. 2005;16:2088-97.

2. Saha MK, Julian BA, Novak J, Rizk DV. Secondary IgA nephropathy. Kidney Int. 2018;94:674-81.

3. Benjegerdes, K. E., K. Hyde, D. Kivelevitch and B. Mansouri. Pustular psoriasis: pathophysiology and current treatment perspectives. Psoriasis (Auckl) 2016; 6: 131-144.

4. Imafuku S, Honma M, Okubo Y, et al. Efficacy and safety of secukinumab in patients with generalized pustular psoriasis: a 52-week analysis from phase III open-label multicenter Japanese study. J Dermatol. 2016;43:1011-7.

5. Trimarchi H, Barratt J, Cattran DC, et al. Oxford classification of IgA nephropathy 2016: an update from the lgA nephropathy classification working group. Kidney Int. 2017;91:1014-21.

6. Zadrazil J, Tichy T, Horak P, et al. IgA nephropathy associated with psoriasis vulgaris: a contribution to the entity of 'psoriatic nephropathy'. J Nephrol. 2006;19:382-6

7. Jiao Y, Xu H, Li H, Li X. Mesangial proliferative glomerulonephritis with or without IgA deposits: the morphological characters in psoriasis vulgaris. Nephron Clin Pract. 2008;108:c221-5.

8. Kagan A, Husza'r M, Frumkin A, Rapoport J. Reversal of nephrotic syndrome due to AA amyloidosis in psoriatic patients on long-term colchicine treatment. Case report and review of the literature. Nephron. 1999:82:348-53.

9. Pradhan SK, Beriha SS. Focal segmental glomerulosclerosis associated with psoriasis. Saudi J Kidney Dis Transpl. 2014;25:670-1.

10. Bagga A, Menon S, Hari P, Mantan M, Dinda A. Nephrotic syndrome preceding psoriasis in children. Pediatr Nephrol. 2007:22:1373-6.

11. Akoglu H, Dede F, Akoglu G, Gonul II, Odabas AR. Membranoproliferative glomerulonephritis associated with psoriasis vulgaris. Ren Fail. 2009;31:858-61.

12. Sakellariou GT, Vounotrypidis $P$, Berberidis C. Infliximab treatment in two patients with psoriatic arthritis and secondary IgA nephropathy. Clin Rheumatol. 2007;26:1132-3.

13. Kluger N, Du-Thanh A, Bessis D, Servel MF, Mourad G. Psoriasis-associated IgA nephropathy under infliximab therapy. Int J Dermatol. 2015;54:e79-80.

14. Jacquet $A$, Francois $H$, Frangie $C$, et al. IgA nephropathy associated with ankylosing spondylitis is not controlled by infliximab therapy. Nephrol Dial Transplant. 2009:24:3540-2

15. Robinson A, Van Voorhees AS, Hsu S, et al. Treatment of pustular psoriasis: from the medical Board of the National Psoriasis Foundation. J Am Acad Dermatol. 2012;67:279-88.

16. Wu W, Debbaneh M, Moslehi H, Koo J, Liao W. Tonsillectomy as a treatment for psoriasis: a review. J Dermatolog Treat. 2014;25:482-6.

17. Rachakonda TD, Dhillon JS, Florek AG, Armstrong AW. Effect of tonsillectomy on psoriasis: a systematic review. J Am Acad Dermatol. 2015; 72:261-75.

18. Thorleifsdottir RH, Sigurdardottir SL, Sigurgeirsson B, et al. Improvement of psoriasis after tonsillectomy is associated with a decrease in the frequency of circulating $T$ cells that recognize streptococcal determinants and homologous skin determinants. J Immunol. 2012;188:5160-5.

19. Sokumbi O, Wetter DA, Makol A, Warrington KJ. Vasculitis associated with tumor necrosis factor-alpha inhibitors. Mayo Clin Proc. 2012;87:739-45.
20. Wei SS, Sinniah R. Adalimumab (TNF alpha inhibitor) therapy exacerbates IgA glomerulonephritis acute renal injury and induces lupus autoantibodies in a psoriasis patient. Case Rep Nephrol. 2013;2013:812781.

21. Ochi M, Toyama $T$, Ando $M$, et al. A case of secondary IgA nephropathy accompanied by psoriasis treated with secukinumab. CEN Case Rep. 2019;8: 200-4.

22. Piga M, Chessa E, lbba $V$, et al. Biologics-induced autoimmune renal disorders in chronic inflammatory rheumatic diseases: systematic literature review and analysis of a monocentric cohort. Autoimmun Rev. 2014;13:873-9.

23. Stokes MB, Foster K, Markowitz GS, et al. Development of glomerulonephritis during anti-TNF-alpha therapy for rheumatoid arthritis. Nephrol Dial Transplant. 2005;20:1400-6.

24. Doulton TW, Tucker B, Reardon J, Velasco N. Antineutrophil cytoplasmic antibody-associated necrotizing crescentic glomerulonephritis in a patient receiving treatment with etanercept for severe rheumatoid arthritis. Clin Nephrol. 2004;62:234-8.

25. Saint Marcoux, B. And M. De Bandt. Vasculitides induced by TNFalpha antagonists: a study in 39 patients in France. Joint Bone Spine 2006;73: 710-713.

26. Di Lernia V. IgA nephropathy during treatment with TNF-alpha blockers: could it be predicted? Med Hypotheses. 2017;107:12-3.

27. Atzeni F, Sarzi-Puttini P. Autoantibody production in patients treated with anti-TNF-alpha. Expert Rev Clin Immunol. 2008;4:275-80.

28. Yilmaz SB, Cicek N, Coskun M, Yegin O, Alpsoy E. Serum and tissue levels of IL-17 in different clinical subtypes of psoriasis. Arch Dermatol Res. 2012;304: $465-9$.

29. Furue M, Furue K, Tsuji G, Nakahara T. Interleukin-17A and keratinocytes in psoriasis. Int J Mol Sci 2020;21:1275.

30. Shiga T, Sato K, Kataoka S, Sano S. TNF inhibitors directly target Th17 cells via attenuation of autonomous TNF/TNFR2 signalling in psoriasis. J Dermatol Sci. 2015;77:79-81.

31. Krueger JG, Brunner PM. Interleukin-17 alters the biology of many cell types involved in the genesis of psoriasis, systemic inflammation and associated comorbidities. Exp Dermatol. 2018;27:115-23.

32. Hawkes JE, Yan BY, Chan TC, Krueger JG. Discovery of the IL-23/IL-17 signaling pathway and the treatment of psoriasis. J Immunol. 2018;201: 1605-13.

33. Lin JR, Wen J, Zhang $H$, et al. Interleukin-17 promotes the production of underglycosylated IgA1 in DAKIKI cells. Ren Fail. 2018:40:60-7.

34. Lin FJ, Jiang GR, Shan JP, et al. Imbalance of regulatory T cells to Th17 cells in IgA nephropathy. Scand J Clin Lab Invest. 2012;72:221-9.

35. Watorek E, Klinger M. IL-17A as a potential biomarker of IgA nephropathy. Pol Arch Med Wewn. 2015;125:204-6.

\section{Publisher's Note}

Springer Nature remains neutral with regard to jurisdictional claims in published maps and institutional affiliations.

Ready to submit your research? Choose BMC and benefit from:

- fast, convenient online submission

- thorough peer review by experienced researchers in your field

- rapid publication on acceptance

- support for research data, including large and complex data types

- gold Open Access which fosters wider collaboration and increased citations

- maximum visibility for your research: over $100 \mathrm{M}$ website views per year

At BMC, research is always in progress.

Learn more biomedcentral.com/submission 